\title{
Platelet-derived growth factor-D induces expression of cyclooxygenase- 2 in rat mesangial cells through activation of PI3K/PKB and PKCs
}

\author{
YU-KYOUNG PARK ${ }^{1}$, BYEONG-CHURL JANG ${ }^{1}$ and MISUN CHOI ${ }^{2}$ \\ Departments of ${ }^{1}$ Medical Genetic Engineering and ${ }^{2}$ Pathology, School of Medicine, \\ Keimyung University, Dalseo-gu, Daegu 704-701, Republic of Korea
}

Received September 3, 2012; Accepted November 2, 2012

DOI: $10.3892 / \mathrm{ijmm} .2012 .1216$

\begin{abstract}
Platelet-derived growth factor (PDGF)-D is suggested to be a key factor in the development of several renal pathologies, including mesangioproliferative glomerulonephritis. Cyclooxygenase (COX)-2 is a protein involved in the biosynthesis of inflammatory prostaglandins. In this study, we investigated the effect of PDGF-D on the regulation of COX-2 expression in rat mesangial cells (RMCs). Treatment with PDGF-D induced COX-2 at both the protein and mRNA levels in RMCs, suggesting that the PDGF-D-mediated induction of COX-2 is due to COX-2 transcriptional upregulation. PDGF-D treatment also led to a rapid but transient activation of PKB and extracellular signal regulated kinase (ERK)-1/2. Activities of JNK-1/2 and p38 MAPK, however, were not influenced by PDGF-D in RMCs. Markedly, pharmacological inhibition studies showed that pretreatment with LY294002 (a PI3K/PKB inhibitor) or GF109203X (a pan-PKC inhibitor) suppressed the PDGF-D-induced expression of COX-2 protein and mRNA, while pretreatment with PD98059 (an ERK-1/2 inhibitor) or PP1 (an Src inhibitor) had no effect on it. These findings collectively demonstrate for the first time that PDGF-D induces COX-2 by transcriptional upregulation in RMCs and the induction is largely related to $\mathrm{PI} 3 \mathrm{~K} / \mathrm{PKB}$ and PKCs activities.
\end{abstract}

\section{Introduction}

Platelet-derived growth factor (PDGF) is a potent mitogen and chemotactic factor for numerous cell types of mesen-

Correspondence to: Dr Misun Choi, Department of Pathology, School of Medicine, Keimyung University, 1095 Dalgubeoldaero, Dalseo-gu, Daegu 704-701, Republic of Korea

E-mail:msc@dsmc.or.kr

Professor Byeong-Churl Jang, Department of Medical Genetic Engineering, School of Medicine, Keimyung University, 1095 Dalgubeoldaero, Dalseo-gu, Daegu 704-701, Republic of Korea

E-mail: jangbc12@kmu.ac.kr

Key words: platelet-derived growth factor-D, cyclooxygenase-2, PKB, extracellular signal regulated kinase-1/2, PKC, rat mesangial cell chymal origin, including glomerular mesangial cells $(1,2)$. To date, four PDGF family members have been identified: PDGF-A, -B, -C and -D (3-6). The PDGF family members exert their biological activities through the cell membrane PDGF receptor (PDGFR), which comprises the $\alpha$ (PDGFR- $\alpha$ ) and $\beta$ (PDGFR- $\beta$ ) chains, with different binding specificities and affinities $(2,7)$. Physiologically, the PDGF system is important in embryonal development, wound healing, and adult maintenance $(4,8,9)$. However, excessive signaling of the system has been implicated in various diseases, including cancer, vasculopathies, fibrosis, and renal pathologies (10-14). Among components of the PDGF system, PDGF-D signaling is suggested to be a key factor in the development of a variety of renal pathologies, including mesangial proliferative glomerulopathy, renal fibrosis, and mesangioproliferative glomerulonephritis $(15,16)$.

Previous studies have suggested the involvement of prostaglandins (PGs) in renal physiology and/or pathology, such as vasodilatation, renin secretion, and sodium and water excretion, and/or renal failure (17-20). Cyclooxygenase (COX) is the rate-limiting enzyme involved in the biosynthesis of PGs and related eicosanoids from arachidonic acid. There are two isoforms of COX: COX-1 and COX-2. COX-1 is constitutively expressed in most cell types and the COX-1-derived PGs are involved in normal inflammatory responses, bone development, and wound healing (21-23). By contrast, COX-2 is an inducible enzyme and its expression is highly increased in cells following the exposure of extracellular stimuli, including interleukin-1 $\beta$, lipopolysaccharide, manganese or growth factor (24-27). Clinical evidence indicates overexpression of COX-2 and its role in several inflammatory and neoplastic diseases (28). Previous studies have demonstrated an upregulation of COX-2 expression in proliferative glomerulonephritis (29) and an increased renal expression of COX-2 in nephropathies $(19,30)$. It has been shown that inhibition of COX-2 by specific COX-2 inhibitors ameliorates renal ablation-induced changes in the kidney function (31) and reduces expression of several mediators of renal injury in a model of diabetes and hypertension (32). These previous findings suggest that exaggerated COX-2 expression and activity may be involved in various renal pathologies. PDGF-D regulation of COX-2 expression in renal cells, however, remains unknown. 
In this study, we investigated the effect of PDGF-D on COX-2 expression in rat mesangial cells (RMCs) and determined possible molecular and signaling mechanisms involved.

\section{Materials and methods}

Materials. RPMI-1640 medium, fetal bovine serum (FBS), penicillin, and streptomycin were purchased from WelGENE (Daegu, Korea). Enzyme-linked chemiluminescence (ECL) western detection reagents were bought from Thermo Scientific (Waltham, MA, USA). Nitrocellulose membrane was bought from Millipore (Rockford, IL, USA). Bradford reagent was purchased from Bio-Rad (Hercules, CA, USA). PDGF-D was purchased from R\&D (Minneapolis, MN, USA). Protease inhibitor cocktail (100X) and PP1 were purchased from Calbiochem (Madison, WI, USA). PD98059, LY294002 and GF109203X were purchased from Biomol (Plymouth Meeting, PA, USA). Antibody of COX-2 was purchased from Cayman Chemical (Ann Arbor, MI, USA). Antibodies of phospho-extracellular signal regulated kinase-1/2 (p-ERK-1/2), total-ERK (T-ERK-1/2), phospho-c-Jun N-terminal kinase-1/2 (p-JNK-1/2), T-JNK-1/2, p-p38 MAPK, T-p38 MAPK, p-PKB and T-PKB were purchased from Epitomics (Burlingame, CA, USA). Other reagents, including anti-actin mouse monoclonal antibody, were purchased from Sigma (St. Louis, MO, USA).

Cell culture. RMCs were grown at $37^{\circ} \mathrm{C}$ in a humidified condition of $95 \%$ air and $5 \% \mathrm{CO}_{2}$ in RPMI-1640 supplemented with $10 \%$ heat-inactivated FBS, $100 \mathrm{U} / \mathrm{ml}$ penicillin, and $100 \mu \mathrm{g} / \mathrm{ml}$ streptomycin.

MTS assay. To measure the effect of PDGF-D and/or pharmacological inhibitors or agents on the viability of RMCs, cells were grown in 96 -well plates at a density of $1 \times 10^{4}$ cells/well in $100 \mu \mathrm{l}$ volume and were serum-starved for $24 \mathrm{~h}$. Cells were then treated without or with PDGF-D in the absence or presence of LY294002, PD98059, GF109203X or PP1 for $24 \mathrm{~h}$, at which time point cells were incubated with MTS $(20 \mu \mathrm{l} /$ well $)$ for $1.5 \mathrm{~h}$ at $37^{\circ} \mathrm{C}$. The absorbance was measured at $595 \mathrm{~nm}$ using a microplate reader. The MTS assay was performed in triplicates. Data are the means \pm standard error (SE) of three independent experiments.

Preparation of whole cell lysates. To measure the effect of PDGF-D on the expression of COX-2 protein in RMCs, cells were plated in 6-well plates at a density of $1 \times 10^{6}$ cells/well in $2 \mathrm{ml}$ volume and were serum-starved for $24 \mathrm{~h}$. Cells were then treated without or with different concentrations of PDGF-D for $24 \mathrm{~h}$. Control or the PDGF-D-treated cells were washed with PBS and exposed to cell lysis buffer [50 mM Tris- $\mathrm{Cl}$ (pH 7.4), $150 \mathrm{mM} \mathrm{NaCl}, 0.1 \%$ sodium dodecyl sulfate, $0.25 \%$ sodium deoxycholate, $1 \%$ Triton X-100, $1 \%$ Nonidet P-40, $1 \mathrm{mM}$ EDTA, $1 \mathrm{mM}$ EGTA, proteinase inhibitor cocktail (1X)]. The cell lysates were collected in a $1.5 \mathrm{ml}$ tube and centrifuged for $20 \mathrm{~min}$ at $4^{\circ} \mathrm{C}$ at $12,000 \mathrm{rpm}$. The supernatant was saved and protein concentrations were determined with the Bradford reagent.

Western blotting. Proteins ( $50 \mu \mathrm{g})$ were separated by SDS-PAGE $(10 \%)$ and transferred onto nitrocellulose membranes
(Millipore). The membranes were washed with TBS (10 mM Tris, $150 \mathrm{mM} \mathrm{NaCl}$ ) supplemented with $0.05 \%$ (vol/vol) Tween-20 (TBST) followed by blocking with TBST containing $5 \%$ (wt/vol) non-fat dried milk. The membranes were incubated overnight with antibodies specific for the protein of interest at $4^{\circ} \mathrm{C}$. The membranes were exposed to secondary antibodies coupled to horseradish peroxidase at room temperature for $2 \mathrm{~h}$. The membranes were washed, and immunoreactivities were detected by ECL reagents.

Reverse transcription-polymerase chain reaction (RT-PCR). To measure the expression levels of PDGFR- $\alpha$ and PDGFR- $\beta$ in RMCs, cells were plated in 6-well plates at a density of $1 \times 10^{6}$ cells/well in $2 \mathrm{ml}$ volume overnight. To measure the effect of PDGF-D on the expression of COX-2 mRNA in RMCs, cells were plated in 6-well plates at a density of $1 \times 10^{6}$ cells/well in $2 \mathrm{ml}$ volume and serum-starved for $24 \mathrm{~h}$. Cells were then treated without or with different concentrations of PDGF-D for $24 \mathrm{~h}$. Total RNA from the conditioned cells above was isolated using the RNAzol-B (Tel-Test, Inc.). Three micrograms of total RNA were reverse transcribed using a random hexadeoxynucleotide primer and reverse transcriptase. Single stranded cDNA was amplified by PCR with the following primers: PDGFR- $\alpha$, forward, 5'-GGC TTC AAC GGA ACC TTC AG-3' and reverse, 5'-CGC TGT CTT CTT CCT TAG CC-3'; PDGFR- $\beta$, forward, 5'-GAG TGC CCT CCC GCA TTG-3' and reverse, 5'-GGT AGA CCA GGT GAC ATT TG-3'; COX-2, forward, 5'-CTG TAC TAC GCC GAG ATT CCT GA-3' and reverse, 5'-GTC CTC GCT TCT GAT CTG TCT TG-3'; GAPDH, forward, 5'-GGT GAA GGT CGG TGT GAA CG-3' and reverse, 5'-GGT AGG AAC ACG GAA GGC CA-3'. The PCR conditions were: PDGFR- $\alpha, 30$ cycles of denaturation at $94^{\circ} \mathrm{C}$ for $30 \mathrm{sec}$, annealing at $50^{\circ} \mathrm{C}$ for $30 \mathrm{sec}$, and extension at $72^{\circ} \mathrm{C}$ for $1 \mathrm{~min}$; PDGFR- $\beta, 35$ cycles of denaturation at $94^{\circ} \mathrm{C}$ for $30 \mathrm{sec}$, annealing at $50^{\circ} \mathrm{C}$ for $30 \mathrm{sec}$, and extension at $72^{\circ} \mathrm{C}$ for $1 \mathrm{~min}$; COX-2, 35 cycles of denaturation at $94^{\circ} \mathrm{C}$ for $30 \mathrm{sec}$, annealing at $56^{\circ} \mathrm{C}$ for $30 \mathrm{sec}$, and extension at $72^{\circ} \mathrm{C}$ for $30 \mathrm{sec}$; GAPDH, 27 cycles of denaturation at $94^{\circ} \mathrm{C}$ for $30 \mathrm{sec}$, annealing at $57^{\circ} \mathrm{C}$ for $30 \mathrm{sec}$, and extension at $72^{\circ} \mathrm{C}$ for $30 \mathrm{sec}$, respectively. GAPDH was used as an internal control to evaluate the relative expression of COX-2.

Statistical analysis. Cell count analysis was performed in triplicates and repeated three times. Data are expressed as the means \pm standard error $(\mathrm{SE})$. Significance $(\mathrm{P}<0.05)$ was determined by one-way ANOVA.

\section{Results}

PDGF-D induces expression of COX-2 at both the protein and mRNA levels in RMCs. There are two types of PDGF receptor (PDGFR); PDGFR- $\alpha$ and PDGFR- $\beta$. PDGF-D binds predominantly to PDGFR- $\beta$. We thus initially measured the expression levels of PDGFR in RMCs using RT-PCR analysis. RMCs expressed mRNA expressions of both PDGFR- $\alpha$ and PDGFR- $\beta$ (Fig. 1A). However, there were much higher expression levels of PDGFR- $\beta$ than PDGFR- $\alpha$. Expression levels of GAPDH mRNA were used as a loading control. After determining the PDGFRs expressed in RMCs, we next analyzed the effect of PDGF-D on the induction of COX-2 protein 
RMC



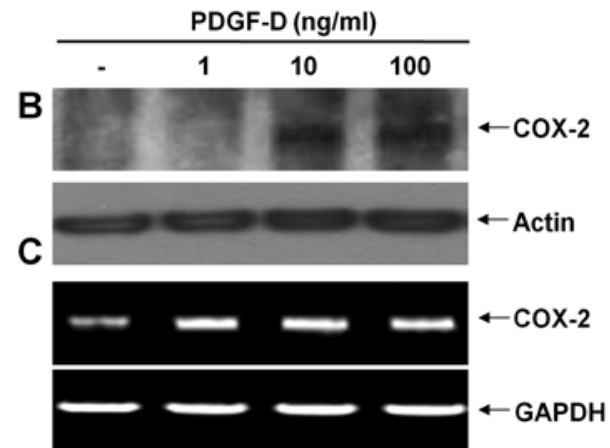

Figure 1. Expression of PDGFRs and effect of PDGF-D on the expression of COX-2 protein and mRNA in RMCs. (A) RMCs were plated in $1 \times 10^{6}$ cells/2 ml/well/6-well plate overnight. Total RNA was prepared and subjected to RT-PCR analysis using specific primers of PDGFR- $\alpha$ and PDGFR- $\beta$, respectively. The image is representative of three independent experiments. (B and C) RMCs seeded in $1 \times 10^{6}$ cells/2 ml/well $/ 6$-well plate the day before treatments were serum-starved for $24 \mathrm{~h}$. Cells were then treated without or with PDGF-D for the indicated concentrations for an additional $24 \mathrm{~h}$. (B) Whole cell lysates and total RNA were prepared, and subjected to western blotting $(\mathrm{C})$ using specific antibody of COX-2 and actin and RT-PCR analysis with specific primers of COX-2 and GAPDH, respectively. The image in (B and C) is representative of three independent experiments.

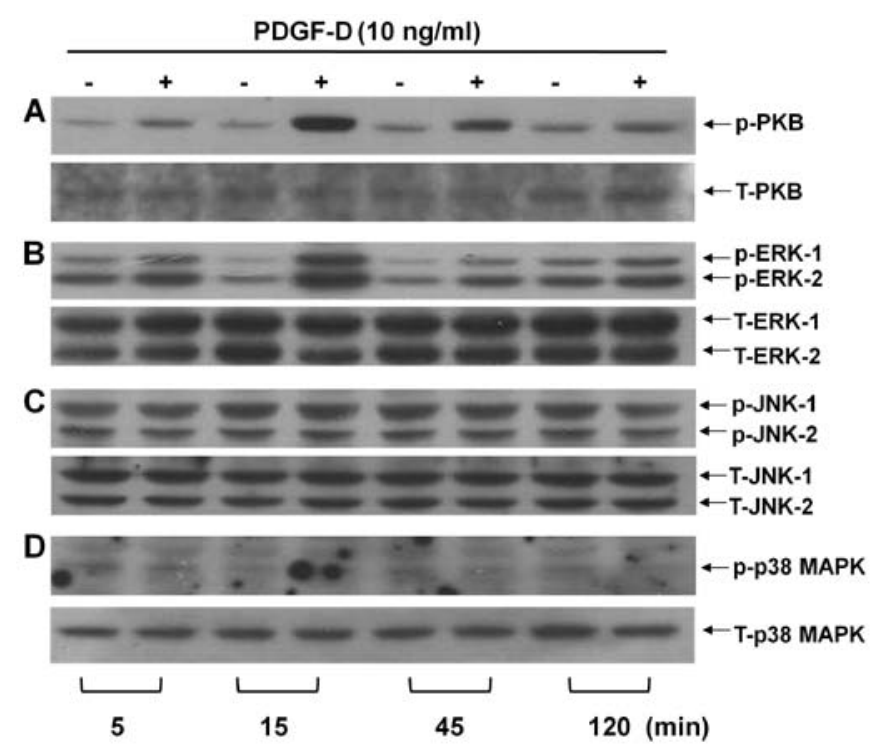

Figure 2. Time course experiments on activation of PKB and the family of MAPKs in the PDGF-D-treated RMCs. RMCs seeded in $1 \times 10^{6}$ cells $/ 2 \mathrm{ml} /$ well/6-well plate the day before treatments were serum-starved for $24 \mathrm{~h}$. Cells were then treated without or with PDGF-D $(10 \mathrm{ng} / \mathrm{ml})$ for the indicated times (5-120 min). Whole cell lysates were prepared, and subjected to western blotting using specific antibody. This image is representative of three independent experiments. p-PKB, phospho-PKB; T-PKB, total-PKB; p-ERK-1/2, phospho-ERK-1/2; T-ERK-1/2, total-ERK-1/2; p-JNK-1/2, phospho-JNK-1/2; T-JNK-1/2, total-JNK-1/2; p-p38 MAPK, phospho-p38 MAPK; T-p38 MAPK, total-p38 MAPK.

and mRNA expressions in RMCs using western blotting and RT-PCR analysis, respectively. COX-2 protein was not detected in control RMCs or RMCs exposed to PDGF-D at $1 \mathrm{ng} / \mathrm{ml}$ for $24 \mathrm{~h}$ (Fig. 1B). However, there was an upregulation of COX-2 protein in RMCs treated with PDGF-D at 10 or $100 \mathrm{ng} / \mathrm{ml}$ for $24 \mathrm{~h}$. Notably, there were low levels of COX-2 mRNA in control RMCs (Fig. 1C). Treatment with PDGF-D even at $1 \mathrm{ng} / \mathrm{ml}$ further enhanced the COX-2 mRNA levels. However, there was no further enhancement by PDGF-D treatment at 10 or $100 \mathrm{ng} / \mathrm{ml}$. Expression levels of control actin protein and GAPDH mRNA remained constant in RMCs treated without or with PDGF-D.
$P D G F-D$ leads to a rapid but transient activation of $P K B$ and ERK-1/2 in RMCs. Due to the strongest COX-2 inducing effect, the $10 \mathrm{ng} / \mathrm{ml}$ concentration of PDGF-D was chosen for further studies. Time course experiments were next used to examine the effect of PDGF-D on the activation of intracellular signaling proteins, herein PKB and the family of MAPKs, in RMCs. Treatment with PDGF-D led to a time-dependent increase in PKB phosphorylation in RMCs (Fig. 2A). PDGF-D treatment even at 5 min slightly enhanced phosphorylation of PKB. Maximal PKB phosphorylation occurred at $15 \mathrm{~min}$, followed by a gradual decline at 45 or $120 \mathrm{~min}$. PDGF-D treatment also resulted in an enhancement of ERK-1/2 phosphorylation in a time-dependent manner (Fig. 2B). In particular, strong ERK-1/2 phosphorylation was induced by 15 min treatment with PDGF-D, followed by a sharp decline thereafter. However, treatment with PDGF-D at the times tested did not change the phosphorylation levels of JNK-1/2 (Fig. 2C) and p38 MAPK (Fig. 2D) in RMCs. Total expression levels of PKB and each member of the MAPK family were not changed by treatment with PDGF-D at the times tested (Fig. 2, low panels). These results suggest that PDGF-D treatment specifically increases the phosphorylation levels of the pre-existing PKB and ERK-1/2 without de novo synthesis of PKB and ERK-1/2.

Activities of PI3K/PKB and PKCs are critical for the PDGF-Dinduced COX-2 expression in RMCs. Pharmacological inhibition studies were next performed to investigate the role of PKB and/or ERK-1/2 activation in the PDGF-D-induced COX-2 expression in RMCs. Pretreatment with LY294002 (LY, a PI3K/PKB inhibitor) strongly suppressed the PDGF-D-induced expression of COX-2 protein and mRNA, but pretreatment with PD98059 (PD, an ERK-1/2 inhibitor) had little effect on the PDGF-D-induced expression of COX-2 protein and mRNA in RMCs (Fig. 3A and B). Using additional pharmacological inhibitors, such as GF109203X (GF, a pan-PKC inhibitor) and PP1 (an Src inhibitor), we also determined the role of PKCs or Src in the induction of COX-2 expression by PDGF-D in RMCs. Pretreatment with GF largely inhibited the PDGF-D effect on the induction of COX-2 protein and mRNA, while pretreatment with PP1 did not (Fig. 3C and D). 

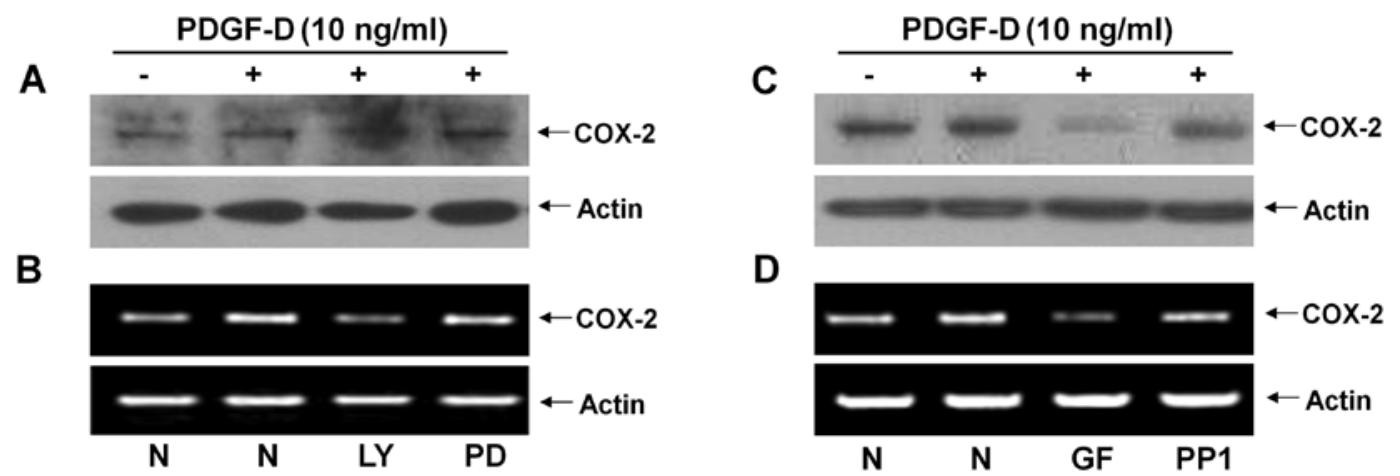

Figure 3. Effect of LY294002, PD98059, GF109203X or PP1 on the PDGF-D-induced expression of COX-2 protein and mRNA in RMCs. RMCs seeded in $1 \times 10^{6}$ cells $/ 2 \mathrm{ml} /$ well $/ 6$-well plate the day before treatments were serum-starved for $24 \mathrm{~h}$. Cells were pretreated without or with LY294002 (a specific inhibitor of PI3K/PKB), PD98059 (a specific inhibitor of ERK-1/2), GF109203X (a pan-PKC inhibitor ) or PP1 (a specific inhibitor of Src) for $1 \mathrm{~h}$, and then treated without or with PDGF-D $(10 \mathrm{ng} / \mathrm{ml})$ in the absence or presence of each inhibitor for an additional $24 \mathrm{~h}$. (A and C) Whole cell lysates and total RNA were prepared and subjected to western blotting (B and D) using specific antibody of COX-2 and actin and RT-PCR analysis with specific primer of COX-2 and GAPDH, respectively. This image is representative of three independent experiments.

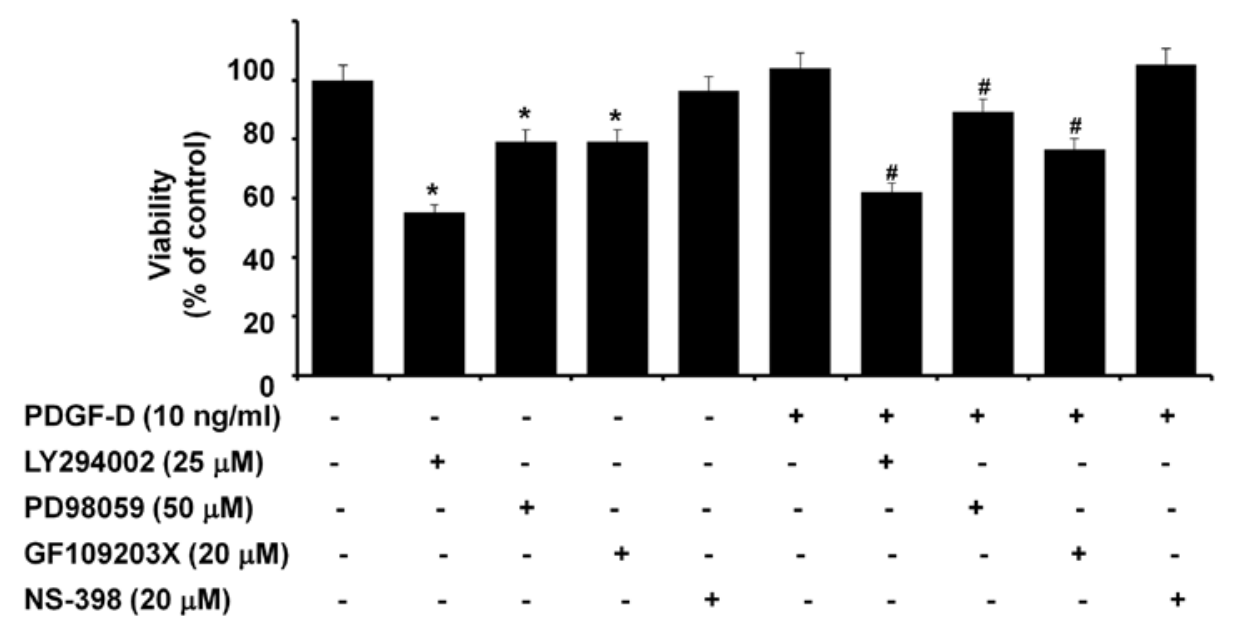

Figure 4. Effect of LY294002, PD98059, GF109203X or NS-398 on the viability of RMCs treated without or with PDGF-D. RMCs seeded in 1x10 4 cells/100 $\mu 1 /$ well/96-well plate the day before treatments were serum-starved for $24 \mathrm{~h}$. Cells were pretreated without or with LY294002 (LY, a specific inhibitor of PI3K/PKB), PD98059 (PD, a specific inhibitor of MEK-1/2, an upstream activator of ERK-1/2), GF109203X (GF, a pan-PKC inhibitor ) or NS-398 (NS, a specific COX-2 enzymatic inhibitor) for $1 \mathrm{~h}$ and then treated without or with PDGF-D $(10 \mathrm{ng} / \mathrm{ml})$ in the absence or presence of each inhibitor for an additional $24 \mathrm{~h}$, followed by measurement of the cell viability by MTS assay. Data are the means $\pm \mathrm{SE}$ of three independent experiments. ${ }^{*} \mathrm{P}<0.05$ compared to the value in the absence of LY, PD or GF. ${ }^{\# P}<0.05$ compared to the value of PDGF-D treatment in the absence of LY, PD or GF.

Activities of PI3K/PKB, ERK-1/2 and PKC (but not COX-2) are necessary for the growth of RMCs. The effect of PDGF-D on the growth of RMCs was next investigated by MTS assay. Treatment with PDGF-D slightly enhanced the viability of RMCs (Fig. 4). The role of COX-2, PKB, ERK-1/2 and/ or PKCs induced or activated by PDGF-D in the growth of RMCs was then evaluated using pharmacological inhibitors, including NS-398 (NS, a COX-2 inhibitor). Pretreatment with LY, PD or GF reduced the viability of RMCs treated with PDGF-D. Notably, there was a similar suppressive effect by LY, PD or GF on the viability of RMCs that were grown in the absence of PDGF-D. However, NS pretreatment did not affect the viability of RMCs treated without or with PDGF-D.

\section{Discussion}

In the present study, we demonstrated for the first time that PDGF-D induces the expression of COX-2 by transcriptional upregulation in RMCs. Moreover, our data suggest that the PDGF-D-induced COX-2 expression in RMCs is at least mediated through modulation of the PI3K/PKB and PKC activities.

Previous studies have shown that PDGF-B, a member of the PDGF family, induces expression of COX-2 in RMCs (33) or rat smooth muscle cells (34). However, PDGF-D regulation of COX-2 expression in renal cells remains unclear. In initial experiments, we have shown that RMCs express high levels of PDGFR- $\beta$, which binds predominantly to PDGF-D (Fig. 1A) and the exposure of PDGF-D into RMCs leads to induction of COX-2 protein expression (Fig. 1B). It is thus evident that the PDGF-D and PDGFR- $\beta$ system is functional in inducing COX-2 in RMCs.

Expression of the $C O X-2$ gene is controlled at multiple levels, including transcription, post-transcription, and translation. It has recently been shown that the PDGF-B-induced COX-2 expression in rat smooth muscle cells is related to both COX-2 transcriptional and post-transcriptional upregulation 
(34). However, there is evidence demonstrating that PDGF-B fails to induce expression of COX-2 mRNA in human gingival fibroblasts pretreated with interleukin-1 $\beta$ (35). The present study shows an upregulation of COX-2 transcripts in the PDGF-D-treated RMCs (Fig. 1C), indicating that the PDGF-D-induced expression of COX-2 protein in RMCs is primarily due to COX-2 transcriptional upregulation.

There are numerous reports suggesting the involvement of the activities of PKB and MAPKs in COX-2 transcriptional upregulation $(26,36,37)$. Earlier investigations have shown activation of PKB, ERK1/2, JNK-1/2 or p38 MAPK and their role in many cellular changes in response to PDGF-D signal. For instance, it has been shown that treatment with PDGF-D (100 ng/ml, $10 \mathrm{~min})$ activates ERK-1/2, which may enhance cell proliferation, in human schwannoma cells (38). In malignant mesothelioma cells, it has been demonstrated that treatment with PDGF-D (40 ng/ml, $10 \mathrm{~min}$ ) leads to activation of Akt and ERK, which may facilitate cell chemotaxis (39). In cultured hepatic stellate cells and myofibroblasts, treatment with PDGF-D (100 ng/ml, $15 \mathrm{~min})$ has been shown to induce phosphorylation of ERK1/2, JNK-1/2, p38 MAPK and PKB, which may contribute to matrix accumulation (40). Herein, we demonstrated that treatment with PDGF-D $(10 \mathrm{ng} / \mathrm{ml})$ rapidly but transiently induced phosphorylation of $\mathrm{PKB}$ and ERK-1/2 but did not influence that of JNK-1/2 and p38 MAPK in RMCs (Fig. 2). It is assumed that PDGF-D may differentially induce activation of the family of MAPKs in a cell type-dependent manner and/or that the differential effect of PDGF-D on activation of the family of MAPKs in previous studies and herein may be due to different experimental conditions used (such as, serum absence vs. presence, $100 \mathrm{ng} / \mathrm{ml}$ vs. $10 \mathrm{ng} / \mathrm{ml}$ of PDGF-D). Notably, in this study, we showed that activation of PI3K/PKB, but not ERK-1/2, is critical for the PDGF-D-induced COX-2 transcriptional upregulation in RMCs (Fig. 3A and B). Previous studies have suggested a role of PKC- $\delta$ in COX-2 expression induced by epidermal growth factor in gliomas (27) or of Src in COX-2 transcriptional and post-transcriptional upregulation induced by PDGD-B in rat smooth muscle cells (34). Although activities of PKCs and Src in response to PDGF-D treatment in RMCs are not measured herein, the present findings further indicate that activities of PKCs and Src are also necessary for the PDGF-D-induced COX-2 transcriptional upregulation in RMCs (Fig. 3C and D).

Evidence suggests that MC proliferation is an early event in various renal pathologies and PDGF-D is involved in MC proliferation in vitro $(15,16)$. In support of the latter, in this study, we demonstrated that PDGF-D treatment leads to a slight increase of the viability of RMCs (Fig. 4). The COX-2dependent and independent MC proliferation have previously been proposed. This notion is based on the fact that some COX-2 metabolites have antiproliferative effects on RMCs $(41,42)$, while COX-2 exerts its antiproliferative effects on mesangial cells or 293 human embryonic kidney cells independently of COX activity $(43,44)$. The present findings that treatment with NS-398, a selective COX-2 inhibitor, does not influence the viability of both control and PDGF-D-treated RMCs (Fig. 4) support no role of the basal or agonist-induced COX-2 (and their metabolites) in the viability of RMCs. There is a large body of evidence suggesting the importance of the activity of intracellular signaling proteins in MC proliferation.
For instance, it has been shown that the activity of ERK-1/2 is necessary for MC proliferation induced by insulin-like growth factor-1, a major mitogenic growth factor for MC (45). It has also been shown that $\mathrm{PI}$ K/PKB activity is linked to PDGF-B-induced MC proliferation (46) and PKC activity is critical for MC proliferation induced by lysophosphatidylcholine, a major component of oxidized-low density lipoproteins (47). The present study suggests that the basal (but not the PDGF-D-induced) activities of PI3K/PKB, ERK-1/2 or PKC are important for the growth of RMCs (Fig. 4). Given that $\mathrm{MC}$ proliferation has been largely attributed to the activity of PI3K/PKB, ERK-1/2 and/or PKC described above, it is suggested that single and/or combined treatments with pharmacological inhibitor of PI3K/PKB, ERK-1/2 or PKC may be useful against renal pathologies in which excess MC proliferation is problematic. Accordingly, a recent study suggested the potential utility of PKC inhibitor as a therapeutic strategy in glomerular disease, which is evidenced by the fact that PKC- $\beta$ inhibition leads to the amelioration of the pathological findings of experimental mesangial proliferative glomerulonephritis (48).

In conclusion, we demonstrated that: i) PDGF-D induces expression of COX-2 through transcriptional upregulation in RMCs, ii) the PDGF-D-induced COX-2 expression in RMCs is at least mediated through the regulation of $\mathrm{PI} 3 \mathrm{~K} / \mathrm{PKB}$ and PKCs activities, iii) the activities of PI3K/PKB, ERK-1/2 and PKCs, but not COX-2, are necessary for the growth of RMCs.

\section{Acknowledgements}

This study was supported by the research promoting grant from the Keimyung University Dongsan Medical Center in 2009.

\section{References}

1. Heldin $\mathrm{CH}$, Eriksson $\mathrm{U}$ and Ostman A: New members of the platelet-derived growth factor family of mitogens. Arch Biochem Biophys 398: 284-290, 2002.

2. Fredriksson L, Li $\mathrm{H}$ and Eriksson U: The PDGF family: four gene products form five dimeric isoforms. Cytokine Growth Factor Rev 15: 197-204, 2004.

3. Betsholtz C, Johnsson A, Heldin CH, Westermark B, Lind P, Urdea MS, Eddy R, Shows TB, Philpott K and Mellor AL: cDNA sequence and chromosomal localization of human plateletderived growth factor A-chain and its expression in tumour cell lines. Nature 320: 695-699, 1986.

4. Heldin $\mathrm{CH}$ and Westermark B: Mechanism of action and in vivo role of platelet-derived growth factor. Physiol Rev 79: 1283-1316, 1999.

5. Li X, Pontén A, Aase K, Karlsson L, Abramsson A, Uutela M, Bäckström G, Hellström M, Boström H, Li H, Soriano P, Betsholtz C, Heldin CH, Alitalo K, Ostman A and Eriksson U: PDGF-C is a new protease-activated ligand for the PDGF alphareceptor. Nat Cell Biol 2: 302-309, 2000.

6. LaRochelle WJ, Jeffers M, McDonald WF, Chillakuru RA, Giese NA, Lokker NA, Sullivan C, Boldog FL, Yang M, Vernet C, Burgess CE, Fernandes E, Deegler LL, Rittman B, Shimkets J, Shimkets RA, Rothberg JM and Lichenstein HS: PDGF-D, a new protease-activated growth factor. Nat Cell Biol 3: 517-521, 2001.

7. Reigstad LJ, Varhaug JE and Lillehaug JR: Structural and functional specificities of PDGF-C and PDGF-D, the novel members of the platelet-derived growth factors family. FEBS J 272: 5723-5741, 2005.

8. Betsholtz C: Biology of platelet-derived growth factors in development. Birth Defects Res C Embryo Today 69: 272-285, 2003.

9. Andrae J, Gallini R and Betsholtz C: Role of platelet-derived growth factors in physiology and medicine. Genes Dev 22: 1276-1312, 2008. 
10. Betsholtz C, Lindblom P, Bjarnegard M, Enge M, Gerhardt $\mathrm{H}$ and Lindahl P: Role of platelet-derived growth factor in mesangium development and vasculopathies: lessons from platelet-derived growth factor and platelet-derived growth factor receptor mutations in mice. Curr Opin Nephrol Hypertens 13: 45-52, 2004.

11. Floege J, Eitner F and Alpers CE: A new look at platelet-derived growth factor in renal disease. J Am Soc Nephrol 19: 12-23, 2008.

12. Bonner JC: Regulation of PDGF and its receptors in fibrotic diseases. Cytokine Growth Factor Rev 15: 255-273, 2004.

13. Raines EW: PDGF and cardiovascular disease. Cytokine Growth Factor Rev 15: 237-254, 2004.

14. Floege J, Eitner F, Van Roeyen C and Ostendorf T: PDGF-D and renal disease: yet another one of those growth factors? J Am Soc Nephrol 14: 2690-2691, 2003.

15. Ostendorf T, van Roeyen CR, Peterson JD, Kunter U, Eitner F, Hamad AJ, Chan G, Jia XC, Macaluso J, Gazit-Bornstein G, Keyt BA, Lichenstein HS, LaRochelle WJ and Floege J: A fully human monoclonal antibody (CR002) identifies PDGF-D as a novel mediator of mesangioproliferative glomerulonephritis. J Am Soc Nephrol 14: 2237-2247, 2003.

16. van Roeyen CR, Ostendorf T, Denecke B, Bokemeyer D, Behrmann I, Strutz F, Lichenstein HS, LaRochelle WJ, Pena CE Chaudhuri A and Floege J: Biological responses to PDGF-BB versus PDGF-DD in human mesangial cells. Kidney Int 69: 1393-1402, 2006.

17. Rios A, Vargas-Robles H, Gámez-Méndez AM and Escalante B: Cyclooxygenase-2 and kidney failure. Prostaglandins Other Lipid Mediat 98: 86-90, 2012.

18. Schneider A and Stahl RA: Cyclooxygenase-2 (COX-2) and the kidney: current status and potential perspectives. Nephrol Dial Transplant 13: 10-12, 1998.

19. Krämer BK, Kammerl MC and Kömhoff M: Renal cyclooxygenase-2 (COX-2). Physiological, pathophysiological, and clinical implications. Kidney Blood Press Res 27: 43-62, 2004.

20. Giovanni G and Giovanni P: Do non-steroidal anti-inflammatory drugs and COX-2 selective inhibitors have different renal effects? J Nephrol 15: 480-488, 2002.

21. Smith WL, DeWitt DL and Garavito RM: Cyclooxygenases: structural, cellular, and molecular biology. Annu Rev Biochem 69: 145-182, 2000

22. Smith WL and DeWitt DL: Prostaglandin endoperoxide $\mathrm{H}$ synthases-1 and -2. Adv Immunol 62: 167-215, 1996.

23. Hla T and Neilson K: Human cyclooxygenase-2 cDNA. Proc Natl Acad Sci USA 89: 7384-7388, 1992.

24. Mitchell JA, Belvisi MG, Akarasereenont P, Robbins RA, Kwon OJ, Croxtall J, Barnes PJ and Vane JR: Induction of cyclooxygenase- 2 by cytokines in human pulmonary epithelial cells: regulation by dexamethasone. Br J Pharmacol 113: 1008-1014, 1994.

25. Wadleigh DJ, Reddy ST, Kopp E, Ghosh S and Herschman HR: Transcriptional activation of the cyclooxygenase-2 gene in endotoxin-treated RAW 264.7 macrophages. J Biol Chem 275: 6259-6266, 2000.

26. Jang BC: Induction of COX-2 in human airway cells by manganese: role of PI3K/PKB, p38 MAPK, PKCs, Src, and glutathione depletion. Toxicol In Vitro 23: 120-126, 2009.

27. Xu K, Chang CM, Gao H and Shu HK: Epidermal growth factordependent cyclooxygenase-2 induction in gliomas requires protein kinase C-delta. Oncogene 28: 1410-1420, 2009.

28. Wang D and Dubois RN: The role of COX-2 in intestinal inflammation and colorectal cancer. Oncogene 29: 781-788, 2010

29. Hirose S, Yamamoto T, Feng L, Yaoita E, Kawasaki K, Goto S, Fujinaka H, Wilson CB, Arakawa M and Kihara I: Expression and localization of cyclooxygenase isoforms and cytosolic phospholipase A2 in anti-Thy-1 glomerulonephritis. J Am Soc Nephrol 9: 408-416, 1998.

30. Khan KN, Stanfield KM, Harris RK and Baron DA: Expression of cyclooxygenase- 2 in the macula densa of human kidney in hypertension, congestive heart failure, and diabetic nephropathy. Ren Fail 23: 321-330, 2001.

31. Wang JL, Cheng HF, Shappell S and Harris RC: A selective cyclooxygenase- 2 inhibitor decreases proteinuria and retards progressive renal injury in rats. Kidney Int 57: 2334-2342, 2000.
32. Cheng HF, Wang CJ, Moeckel GW, Zhang MZ, McKanna JA and Harris RC: Cyclooxygenase-2 inhibitor blocks expression of mediators of renal injury in a model of diabetes and hypertension. Kidney Int 62: 929-939, 2002.

33. Goppelt-Struebe M, Rehm M and Schaefers HJ: Induction of cyclooxygenase- 2 by platelet-derived growth factor (PDGF) and its inhibition by dexamethasone are independent of NF-kappaB/ IkappaB transcription factors. Naunyn Schmiedebergs Arch Pharmacol 361: 636-345, 2000.

34. Xu K, Kitchen CM, Shu HK and Murphy TJ: Platelet-derived growth factor-induced stabilization of cyclooxygenase $2 \mathrm{mRNA}$ in rat smooth muscle cells requires the c-Src family of proteintyrosine kinases. J Biol Chem 282: 32699-32709, 2007.

35. Nakao S, Ogata Y, Yamamoto Y, Furuyama S and Sugiya H: Platelet-derived growth factor-induced arachidonic acid release for enhancement of prostaglandin $\mathrm{E}(2)$ synthesis in human gingival fibroblasts pretreated with interleukin-1beta. J Cell Biochem 92: 579-590, 2004.

36. Dean JL, Brook M, Clark AR and Saklatvala J: p38 mitogenactivated protein kinase regulates cyclooxygenase-2 mRNA stability and transcription in lipopolysaccharide-treated human monocytes. J Biol Chem 274: 264-269, 1999.

37. Guan Z, Buckman SY, Miller BW, Springer LD and Morrison AR: Interleukin-1beta-induced cyclooxygenase-2 expression requires activation of both c-Jun NH2-terminal kinase and p38 MAPK signal pathways in rat renal mesangial cells. J Biol Chem 273 28670-28676, 1998.

38. Ammoun S, Flaiz C, Ristic N, Schuldt J and Hanemann CO Dissecting and targeting the growth factor-dependent and growth factor-independent extracellular signal-regulated kinase pathway in human schwannoma. Cancer Res 68: 5236-5245, 2008

39. Okada A, Yaguchi $T$, Kanno $T$, Gotoh $A$, Nakano $T$ and Nishizaki T: PDGF-D/PDGF- $\beta \beta$ receptor-regulated chemotaxis of malignant mesothelioma cells. Cell Physiol Biochem 29: 241-250, 2012.

40. Borkham-Kamphorst E, van Roeyen CR, Ostendorf T, Floege J, Gressner AM and Weiskirchen R: Pro-fibrogenic potential of PDGF-D in liver fibrosis. J Hepatol 46: 1064-1074, 2007.

41. Menè P, Abboud HE and Dunn MJ: Regulation of human mesangial cell growth in culture by thromboxane A2 and prostacyclin. Kidney Int 38: 232-239, 1990.

42. Stahl RA, Thaiss F, Haberstroh U, Kahf S, Shaw A and Schoeppe W: Cyclooxygenase inhibition enhances rat interleukin 1 beta-induced growth of rat mesangial cells in culture. Am J Physiol 259: 419-424, 1990.

43. Zahner G, Wolf G, Ayoub M, Reinking R, Panzer U, Shankland SJ and Stahl RA: Cyclooxygenase-2 overexpression inhibits platelet-derived growth factor-induced mesangial cell proliferation through induction of the tumor suppressor gene p53 and the cyclin-dependent kinase inhibitors p21waf-1/cip-1 and p27kip-1. J Biol Chem 277: 9763-9771, 2002.

44. Trifan OC, Smith RM, Thompson BD and Hla T: Overexpression of cyclooxygenase-2 induces cell cycle arrest. Evidence for a prostaglandin-independent mechanism. J Biol Chem 274: 34141-34147, 1999.

45. Shibata T, Tamura M, Kabashima N, Serino R, Tokunaga M, Matsumoto M, Miyamoto T, Miyazaki M, Furuno Y, Takeuchi M, Abe H, Okazaki M and Otsuji Y: Fluvastatin attenuates IGF-1induced ERK1/2 activation and cell proliferation by mevalonic acid depletion in human mesangial cells. Life Sci 84: 725-731, 2009.

46. Mitchell D, Rodgers K, Hanly J, McMahon B, Brady HR, Martin $\mathrm{F}$ and Godson C: Lipoxins inhibit Akt/PKB activation and cell cycle progression in human mesangial cells. Am J Pathol 164: 937-946, 2004

47. Bassa BV, Noh JW, Ganji SH, Shin MK, Roh DD and Kamanna VS: Lysophosphatidylcholine stimulates EGF receptor activation and mesangial cell proliferation: regulatory role of $\mathrm{Src}$ and PKC. Biochim Biophys Acta 1771: 1364-1371, 2007.

48. Tokuyama H, Kim S, Zhang Y, Langham RG, Cox AJ, Gow RM, Kelly DJ and Gilbert RE: Protein kinase $C \beta$ inhibition ameliorates experimental mesangial proliferative glomerulonephritis. Nephrology (Carlton) 16: 649-655, 2011. 